\title{
Emotional Intelligence as a Factor of Corporate Culture
}

\author{
Maria Petrovna Prokhorova \\ Department of innovative management technologies \\ Kozma Minin Nizhny Novgorod State Pedagogical University \\ Nizhny Novgorod, Russia
}

\section{Angelika Arkadievna Shkunova}

Department of innovative management technologies Kozma Minin Nizhny Novgorod State Pedagogical University

Nizhny Novgorod, Russia

\author{
Tatyana Evgenievna Lebedeva \\ Department of innovative management technologies \\ Kozma Minin Nizhny Novgorod State Pedagogical Univer- \\ sity \\ Nizhny Novgorod, Russia
}

\author{
Nadezhda Leonidovna Sineva \\ Department of innovative management technologies \\ Kozma Minin Nizhny Novgorod State Pedagogical Univer- \\ sity \\ Nizhny Novgorod, Russia
}

\author{
Svetlana Nikolaevna Kaznacheeva \\ Department of innovative management technologies \\ Kozma Minin Nizhny Novgorod State Pedagogical University \\ Nizhny Novgorod, Russia
}

\begin{abstract}
The article studies the main components of the emotional intelligence of managers and employees of various organizations and fields. An analysis of sources showed that components of emotional intelligence are as follows: interpersonal understanding of the concept, emotional expressiveness, emotional awareness, behavioral intentions. The study was conducted using a google form posted in the electronic courses of Nizhny Novgorod University in courses designed for continuing education. It was revealed that the semantic content of the concept "emotional intelligence" is different for employees and managers of organizations. Changes in emotional intelligence are determined by the development of its components: interpersonal understanding of emotions, emotional expressiveness, emotional awareness, empathy, behavioral intentions. In organizations, positive personal qualities prevail. It is the norm for building interaction, developing a corporate culture based on creativity, relationships, and selfdevelopment. The results obtained can be of practical importance for the development of training technology for a specific organization, which would not contradict the organizational culture.
\end{abstract}

Keywords - emotional expressiveness, emotional awareness, behavioral intentions, corporate culture.

\section{INTRODUCTION}

Managing an organization through the development of a corporate culture is one of the most successful management approaches [1,2]. The development of the corporate culture is identical with stages of development of the organization itself. Currently, it slows down the process of changes in any organi- zation. In the current situation, development of the of corporate culture is associated with "emotional intelligence".

Some time ago, the substantive aspect of competence included control - measuring tools to determine the intelligence level of future employees, in order to predict whether they will benefit their organizations [3]. The recognition of "emotional intelligence" as a more significant success factor is growing. Studies show that 95 percent of staff managers think that "emotional intelligence" is critical because it allows employees to regulate their emotions. Workers who are able to cope with their feelings are more likely to demonstrate empathy and understanding, choose constructive ways to resolve conflict situations. "Emotional intelligence" forms a different system of behavioral reactions [4,5]. Instead of constant supervision and mediation, employees know how to solve problems and encourage the best qualities of their colleagues. As practice shows, hiring employees based on emotional intelligence can create stronger teams; emotional intelligence is important for the corporate culture [6]. According to American and Russian scientists, the basis of emotional intelligence is the model of managerial interaction, the structure of manager's personal qualities [3]

\section{MATERIALS AND MethodS}

An analysis of studies of emotional intelligence by Kravtsova [7], Lyusina, Maryutina, Stepanova [8], Vorobevoy [9], Perkova, Schetinina, and Kabanova [1], showed the significance of this concept, but the lack of a clear understanding of the substantive aspect of the managerial interaction model, which formed the basis for the development of the corporate culture 
The work of any manager is facilitated by emotionally intelligent employees [10]. When the team leader gives feedback, he does not perceive it as a personal insult. Employees know their strengths and weaknesses and want to improve. This dynamic creates truly effective and growth-oriented aspirations, because employees and managers speak the same language and are focused on the same goals.

In Russia, the concept of emotional intellect is associated with the lack of professional methods that could serve as tools for finding such employees [11]. According to the authors, this may be due cultural differences in perceiving human resources. At present, Russia has been swept by a wave of stereotypes, as a result of which the labor market is becoming more diverse and oversaturated, while quality of the workforce is not getting higher. A joint study by the HeadHunter and the Department of Labor and Social Protection of Moscow showed that $27 \%$ of respondents found it difficult to find jobs due to their age. About $88 \%$ of older respondents noted that it was difficult for the, to find a job, and the probability of finding it was only $9 \%$ for people aged 45 and older. According to the forecasts, in the near future employers will face a demographic hole that will lead to a shortage of employees aged 3035 , and there will be a rapid increase in the number of employers registered by the HeadHunter (more than $40 \%$ since 2016). A sharp jump in the job competition is expected in a few years competition. It will be especially acute in companies where age discrimination is considered normal. Many leading companies understand that a decrease in the number of $45+$ aged candidates is not good for them, and are developing programs to work with employees and candidates of this age category.

Thus, the use of emotional intelligence is a relevant and promising direction in the development of modern management science.

An active study of emotional intelligence is associated with a clear understanding of its main components [12,13]. It is worth noting that the content, components of emotional intelligence depend on the content of corporate culture that already exists in organizations [2]. Particular attention is paid to the development of socio-psychological methods to improve the efficiency of modern organizations, universal methods by which the diagnosis of emotional intelligence would be possible, while its carriers would be interested in the development and self-development within a team [3].

First, theorists of economics and managers believe that organizational changes are possible through the development of a corporate culture that is supported by leaders [14,15]. Values should be equally accepted and shared by all members of the management team $[16,17]$.

Secondly, in modern practice, in management models, managers focus on effectiveness, a collective result, but this process is not always accompanied by a stable system of relationships in the team, which leads to the development of motives for self-knowledge and development, and most importantly increases "sensitivity" to consumer requests $[18,19]$.

Thirdly, top managers and consultants in the field of human resources management need a clear understanding of what "emotional intelligence" is required for Russia in order to develop various programs for the use and development of labor force $[20,21]$.

The authors focused on the following issues:

- What is "emotional intelligence"?

- What are the components of "emotional intelligence?"

- Are future managers' reactions incorporated into situations based on emotional intelligence?

- What recommendations will be made when choosing a method for diagnosing emotional intelligence in an organization

The aim of the study was to identify personal characteristics of leaders who form the basis of emotional intelligence.

The authors identified the following objectives of the study:

- to determine the degree to which managers understand the importance of emotional intelligence in managing an organization;

- to identify situations - barriers requiring the manifestation of emotional intelligence;

- to formulate expectations of employees regarding the management process associated with the manifestation of emotions by their leaders.

The study was conducted by the University n.a. Minin in the 2019-20 academic year. The study involved leaders of different organizations and different levels of management. Conventionally, all respondents were divided into two groups: managers and employees. The total number of respondents was 87 people. The study was conducted through a google form posted in electronic courses developed by the University n.a. Minin in courses designed for continuing education $[22,23]$. The questionnaire contained 5 closed-ended questions; respondents chose several answer options for each question. The results were interpreted and supplemented by the answers of the respondents obtained during the discussion of the questionnaire, as well as during training.

\section{RESULTS}

The study was conducted according to several criteria:

- Understanding of the meaning of emotional intelligence;

Emotional expressiveness; (Expectations of managers, expectations of employees)

Emotional awareness;

-Behavioral intentions

. The primary task of the authors was to understand the meaning of the concept "emotional intelligence" by the managers and employees.

The first question was aimed at understanding the meaning of the concept "emotional intelligence" 


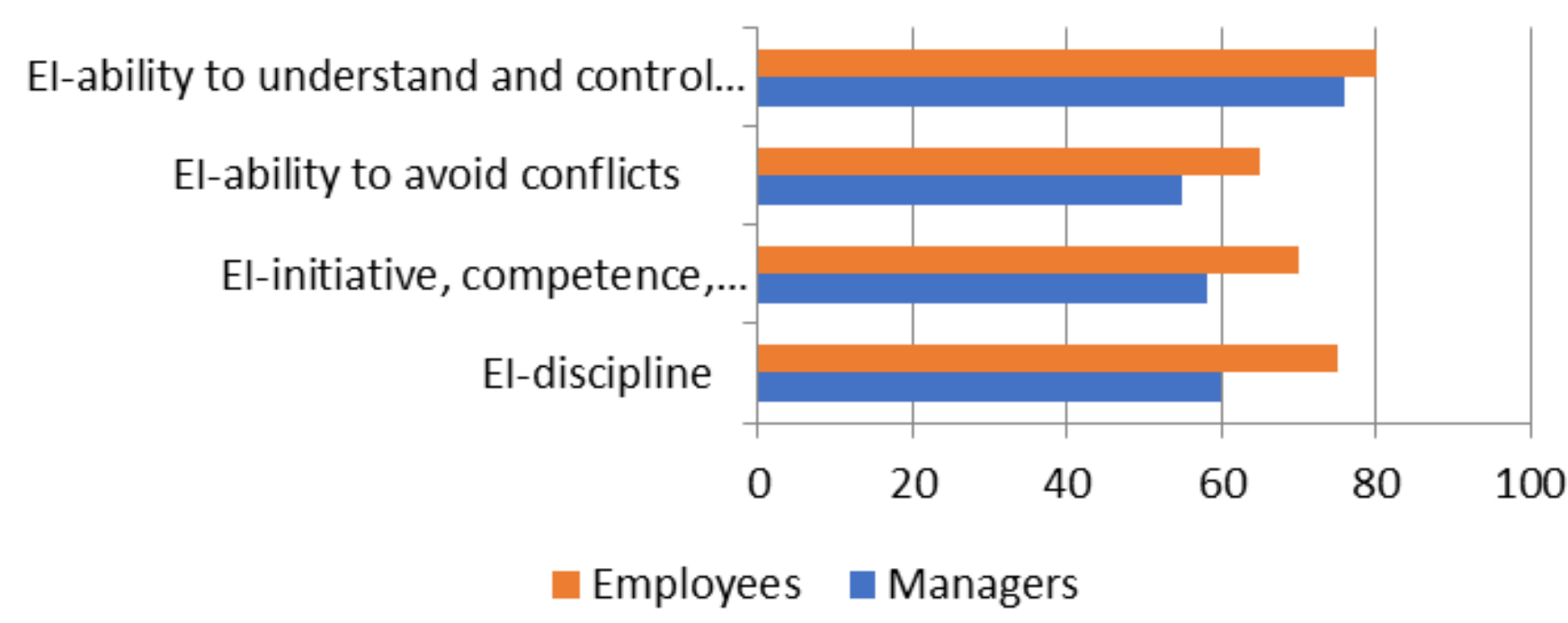

Fig 1. The understanding of the concept "emotional intelligence" by managers and employees

Figure 1 shows that all respondents can be divided into two groups. In one range (from 50 to $70 \%$ ), respondents understand emotional intelligence as an initiative, competence, staff professionalism. Within a separate group (managers, employees), the understanding of this concept is the same. In another range, the concept "emotional intelligence" is understood as managing own emotions and emotions of other people. According to the authors, this is due to the fact that managers and subordinates do not pay attention to the role of emotional intelligence when building relationships within an organization

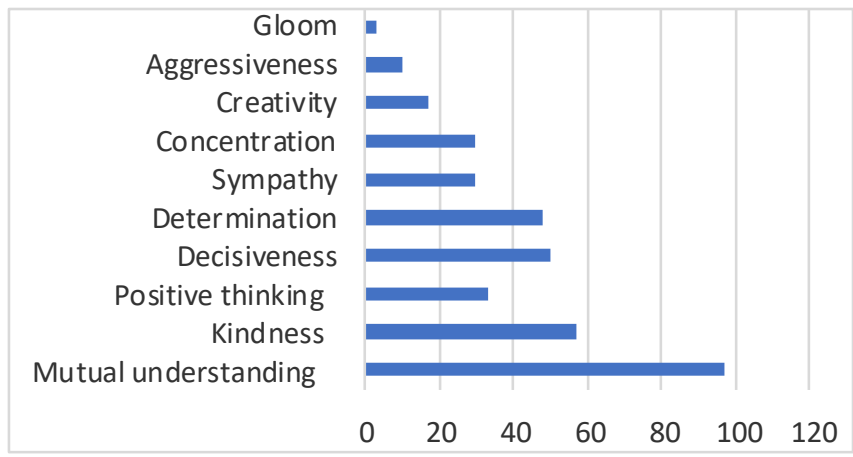

Fig 2. Meanings of qualities of emotional intelligence according to employees.

Qualities are arranged according to the degree of their importance and related to the expectations of employees for the development of these qualities in managers. Assessing the qualities appreciated by employees, it should be noted that out of ten positions, half of the answers were indicated, the answers ranged from two to five of the most basic positions.
Employees wanted to see their most important qualities as mutual understanding $(80 \%)$, goodwill $(50 \%)$, determination $(40 \%)$. Less than half of respondents believe that managers should show sympathy to organizational situations.

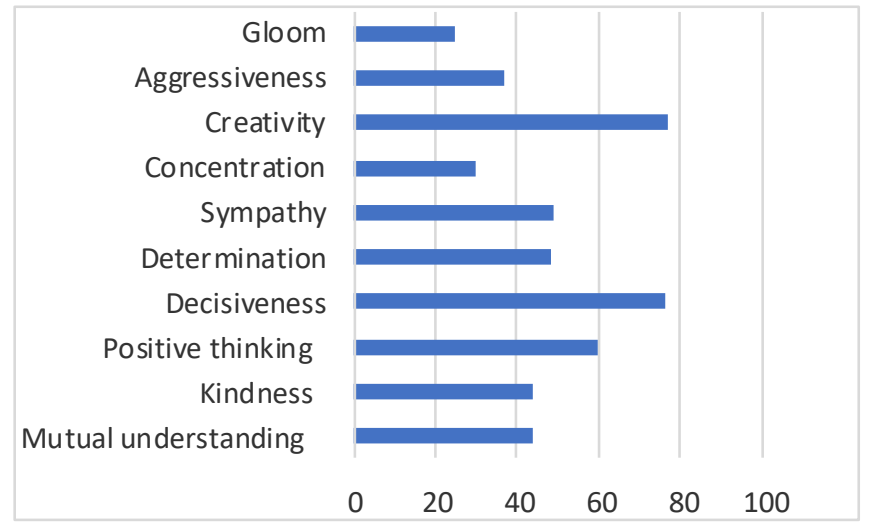

Fig. 3. Meanings of qualities of emotional intelligence according to managers.

Qualities are arranged according to their importance and related to the expectations of managers.

Figure 3 shows that managers want their employees to be creative (80\%), determined and positive (above 50\%). To a lesser degree, respondents mentioned such qualities as friendliness and mutual understanding. Employees want their managers to have the same qualities. Thus, the expectations of the two groups of respondents are different 


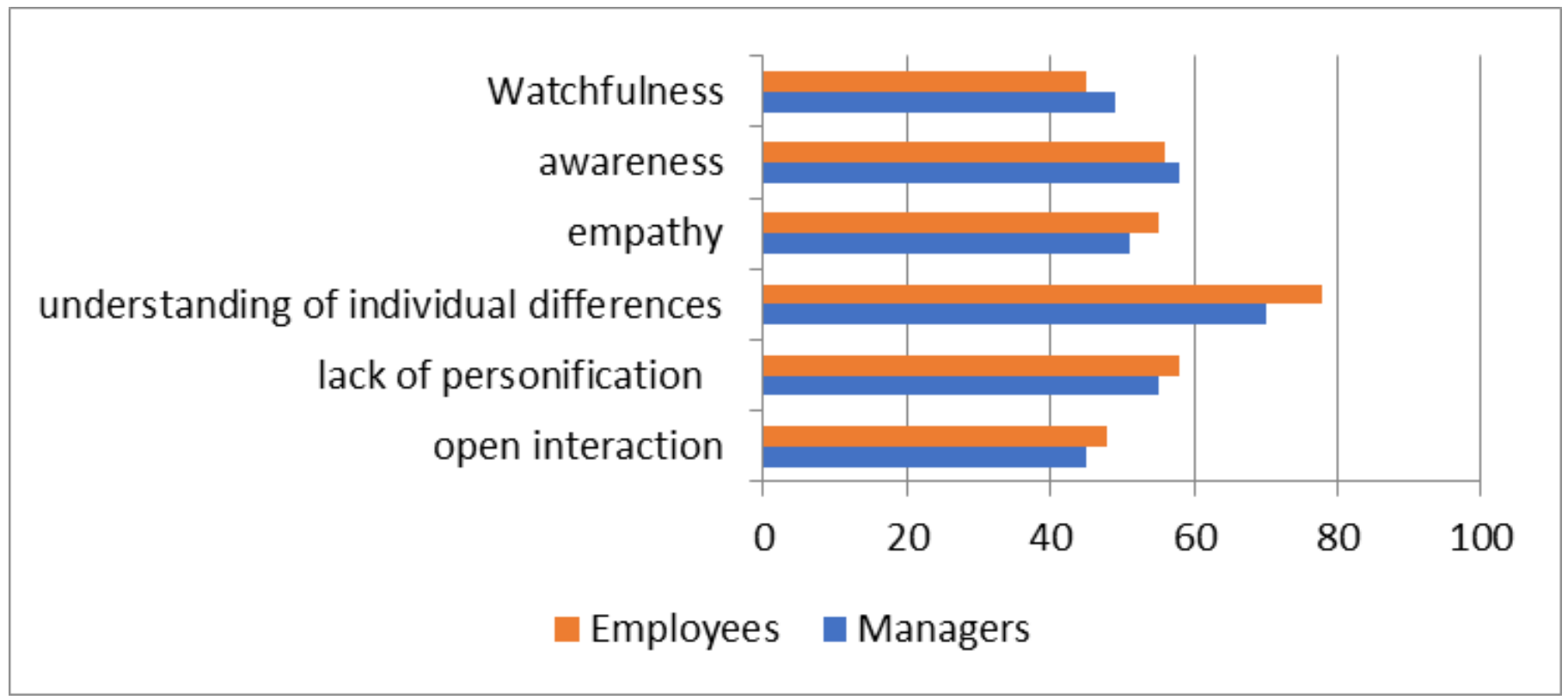

Fig 4. Emotional awareness

A low percentage for the criterion "observation" (below $50 \%$ ) is a sign of insufficient development of the ability to perceive events from different points of view. Employees and managers observe others, but are not able to improve themselves in the process of perception, evaluate their style of perception and thinking. As an additional survey showed, it is difficult for managers to describe diverse aspects of a situation. According to the authors, this is due to the lack of skills when selecting and analyzing information.

According to the criterion "cognitive awareness" (over $55 \%$ ), both managers and employees understand and recognize strengths and limitations of their thinking style (problem research). As a rule, these abilities are combined with the development of openness with respect to the ideas other than those proposed. According to the additional survey, managers and employees prefer making decisions after careful group reflection. It allows them to notice efforts of others and tension. They assess their level of competence or incompetence in each particular case.

For questions about "empathy", the analysis showed a low percentage (slightly above 50\%). According to the authors, this means that managers and employees accept and encourage opinions of others. An additional survey showed that students appreciate what others think, how they interact and feel. They understand feelings of others, their behavior. At the same time, it turned out that co-workers do not understand what quality of feedback is required, so that others would understand that their problems did not go unheard. This is due to the insufficient development of communicative skills (the ability to listen, use non-verbal means of communication for a specific situation).

A high percentage for the criterion "understanding individual differences" $(70 \%)$ means that managers and employees are aware of the importance of differences in their standard behavior. If it is necessary to solve the problem, managers and employees will seek various opinions and encourage efforts of those who have other values and views. This is due to such skills as the ability to know their own individual psychological characteristics; evaluate one's mental state; realize versatile perception and understand colleagues, team members.

A high percentage for the criterion "lack of personification" (about 60\%) means that employees feel confident in their thinking style, they can easily solve problems without connecting them with their own personality. In case of different positions, he does not consider statements of the opposite side as directed against him. He tries to solve the problem not provoking conflicts.

An average indicator for the criterion "open interaction" is a sign that employees are more oriented towards forecasts of organizational situations. Managers and employees are open to changes. They are convinced of their ideas and feelings, but they are ready to change them if they are useless. 


\section{Understand the organization event}

Predict the organization event

\section{Influence the organization event}

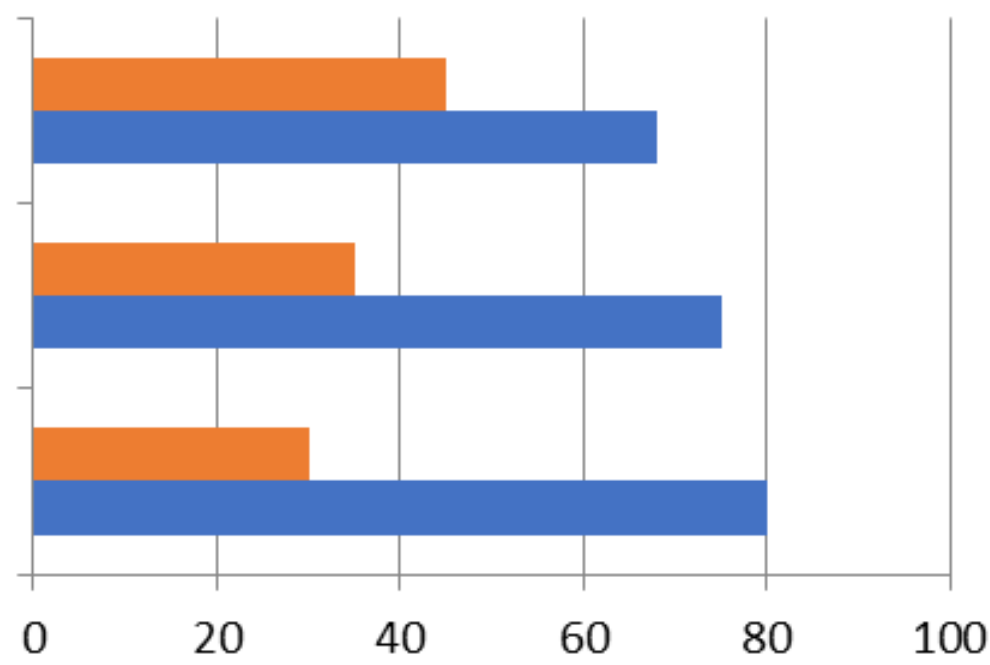

\section{Employees Managers}

Fig 5. Behavioral intentions of respondents

Figure 5 shows that managers are more focused on understanding the organizational event than employees (over $60 \%$ of respondents). An additional survey showed that they are ready to use personal experience obtained through previous observations in order to understand the events. The explanations given by employees should be thoroughly checked, those facts that are based on strong argumentation are chosen to solve, the emotional experience of employees is used to form behavior to a lesser extent. The diagram shows the predominance of the impact on the organizational event. Interviews and personal conversations help relate this event to the fact that the impact depends on the significance of those risks that managers bear in the decision-making process.

TABLE 1. COMPONENTS OF EMOTIONAL INTELLIGENCE THAT CONTRIBUTE TO ORGANIZATIONAL CULTURE

\begin{tabular}{|l|l|l|l|}
\hline Factors & $\begin{array}{l}\text { Emotional } \\
\text { expressiveness }\end{array}$ & $\begin{array}{l}\text { Emotional aware- } \\
\text { ness }\end{array}$ & $\begin{array}{l}\text { Behavioral In- } \\
\text { tent }\end{array}$ \\
\hline Executives & $\begin{array}{l}\text { Creativity } \\
\text { Determination }\end{array}$ & $\begin{array}{l}\text { Understand indi- } \\
\text { vidual differences } \\
\text { Openly interact } \\
\text { Show empathy }\end{array}$ & $\begin{array}{l}\text { Understand the } \\
\text { event } \\
\text { Predict the event } \\
\text { Affect the event }\end{array}$ \\
\hline Staff & $\begin{array}{l}\text { Understanding } \\
\text { e } \\
\text { Goodwill } \\
\text { Determination }\end{array}$ & $\begin{array}{l}\text { Understand indi- } \\
\text { vidual differences } \\
\text { Openly interact } \\
\text { Show empathy }\end{array}$ & $\begin{array}{l}\text { Understand the } \\
\text { event } \\
\text { Predict the event } \\
\text { Affect the event }\end{array}$ \\
\hline
\end{tabular}

\section{DISCUSSION}

The problems, the history of the study of emotional intelligence, methods measuring it, and the correlation with the concept "emotional leadership" made it possible to use the definition proposed by D.V. Lyusin. The development of emotional intelligence is possible by changing its component structure [15]. By the component structure, the authors understand forms of relationships, external emotional expressiveness, emotional awareness, empathy, and emotional exhaustion. This position broadens the understanding of emotional intelligence, forming a new field for exploring its connection with personal characteristics, ethical and cognitive abilities, and gender differences.

Speaking of emotional expressiveness, it can be argued that emotions can be a manifestation of individual duality. Many employees are active during the working day and are oriented towards positive conditions, while other employees are not happy with the work process.

Positive effectiveness (PA) is a tendency to experience positive emotional states. This is expressed by such qualities as sociability, aggression. On the contrary, some people have high negative effectiveness (HC), which is a tendency to experience negative emotions. Employees are often annoyed because they focus on negative aspects of their lives [15,29].

Emotions affect relationships, but these two concepts are different. Emotions are experiences, and relationships are judgments. Emotions are associated with a broader concept of relationships. Relations are a group of beliefs, feelings and behavioral intentions in relation to the job or the team 


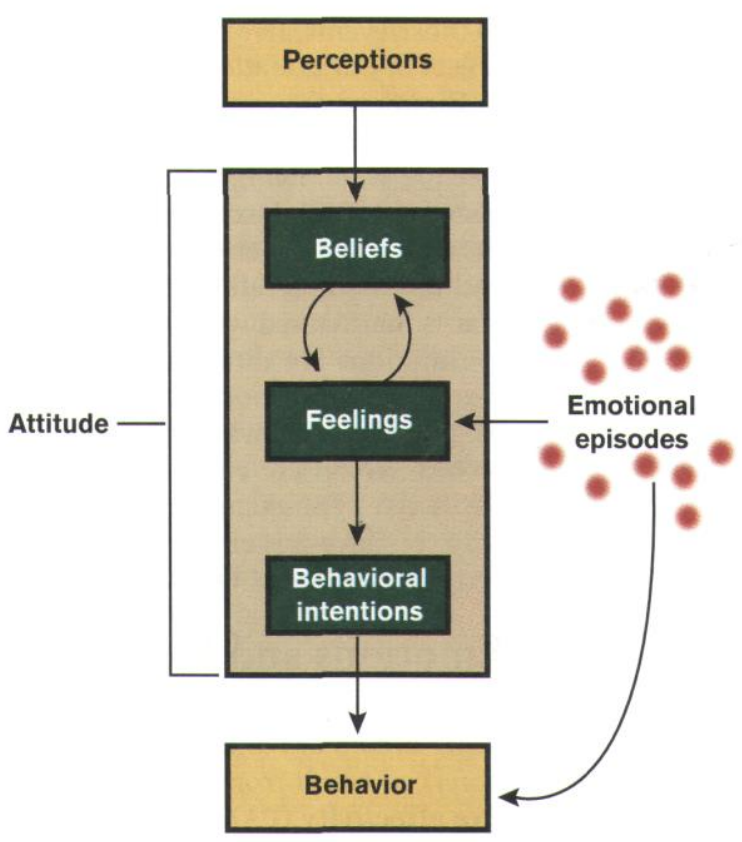

Fig 6. The relationship of relations and emotions.

The relationship between beliefs and feelings is a complex process, because feelings influence beliefs. Managers and employees change their behavioral intentions which is based on the process of perception.

Emotional awareness is all forms of knowledge (images of perception, representation, imagination) associated with cognition of the personality of another person and the culture of interaction. Emotional awareness is used as one of the main criteria for evaluating the critical thinking of managers and employees.

Empathy is the understanding of what people think, feel inside the organization and how they can change the course of events. A real understanding of the working environment is the main truth in organizations, because organizations have a profound effect on people. You need to know why organizational events occur and predict what to expect. In other words, it is necessary to plan organizational events in such a way as to feel confident in a situation that requires high-quality decisionmaking. In this regard, the leader should be able to:

-understand an organizational event;

-predict an organizational event;

- influence the organizational event.

To understand an organizational event means to use personal experience gained through previous observations. Some of these personal theories can be very accurate in understanding people's behavior in many situations. The field of organizational behavior uses scientific methods and applied logic to test accuracy of personal theories in organizational settings.
To predict an organizational event. Decisions and actions are determined by a complex combination of factors. In order to influence organizational events, it is necessary to investigate this event and predict it. Decision-making is not aimed at changing qualitative characteristics of the environment. The manager should influence the human resource itself.

\section{V.CONCLUSION}

This study does not exhaust all aspects of the problem of corporate culture in terms of emotional intelligence. However, it is possible to identify actual significant findings.

Firstly, the semantic content of the concept "emotional intelligence" is different for employees and managers. The expectations of managers are determined by creativity and determination of employees. Employees want managers to possess such qualities as mutual understanding, goodwill, determination

Secondly, changes in emotional intelligence are determined by the development of its components: interpersonal understanding of emotions, emotional expressiveness, emotional awareness, empathy, behavioral intentions.

Thirdly, in Russian companies, there is a tendency to understand an organizational event, predict an organizational event and impact an organizational event.

Fourth, in organizations, positive personal qualities prevail. It is the norm for building interaction, forming an organizational culture based on creativity, relationships, and selfdevelopment.

In conclusion, a change in the managerial interaction model due to the development of emotional intelligence affects the dynamics of e development of corporate culture. An adequate method for developing qualities of emotional intelligence can be a training technology that does not contradict the corporate culture.

\section{References}

[1] L.A. Kabanova, E.V. Yashkova, A.A. Shkunova, N.L.Sineva, A.O Egorova, O.I. Kuryleva, " Study of the strategy of forming organizational culture in Russian enterprises," Opcion, vol. 34 (85), pp 1745-1752, 2018

[2] A.A., Shkunova, E.V.Yashkova, N.L. Sineva, A.O. Egorova, S.N Kuznetsova, "General trends in the development of the organizational culture of Russian companies," Journal of Applied Economic Sciences, vol. XII no 8 (54). pp. 2472-2480, 2017.

[3] E.V.Yashkova, N.L.Sineva, A.A. Shkunova, N.V. Bystrova., Z.V Smirnova, T.V. Kolosova, "Development of innovative business model of modern manager's Qualities," International Journal of Environmental and Science Education, vol. 11, no.11 pp. 4650-4659, 2016

[4] L.K. Ilyashenko, S. M. Markova, A. G. Mironov, Zh. V.Smirnova, O. I Vaganova, "Educational environment as a development resource for the learning process," Amazonia Investiga, vol. 8, Issue, 18, pp. 303-312, 2019

[5] A.V Ponachugin., Yu.N. Lapygin, " Digital educational resources of the university: design, analysis and examination," Vestnik of Minin University, vol. 7, no.2. pp. 5, 2019

[6] O.I. Vaganova, T.E. Lebedeva, M.P.Prokhorova, Zh. V.Smirnova, A.A Shkunova, "Pedagogical support of the educational and information environment," Espacios, vol. 40 no 2. pp. 21-28, 2019. 
[7] A.K. Kravtsova, "Type of managerial interaction of leaders and emotional intelligence," Modern studies of social problems No. 6 (14) Retrieved from: http://sisp.nkras.ru/eru/issues/2012/6/kravtsova.pdf (2012).

[8] D.V., Lyusin, O.O.Maryutina, A.S Stepanova," Structure of emotional intelligence and the connection of its components with individual characteristics: an empirical analysis," Social Intelligence. Theory, Measurement, Research Ed. D.V. Lyusina, D.V. Ushakova. - M.: Institute of Psychology RAS, pp. 129-140, 2004.

[9] E.V. Vorobyeva, M.A. Perkov, D.P Schetinina, "Investigation of the relationship between the adoption of aggression and emotional intelligence,"Russian Psychological Journal, pp. 28-50, 2017.

[10] M.L Gruzdeva, O.I. Vaganova, S.N. Kaznacheeva, N.V. Bystrova, A.V. Chanchina, "Modern Educational Technologies in Professional Education," Lecture Notes in Networks and Systems vol.73, pp. 1097 1103, 2020.

[11] A.V.Listikova., E.E. Egorov, T.E. Lebedeva, S.V. Bulganina, M.P. Prokhorova, "Research of the Best Practices of Artificial Intelligence in the Formation and Development of Personnel," Lecture Notes in Networks and Systems vol.73, pp. 1345-1352, 2020.

[12] F. H. Thomas, "Getting to Know Your Students and an Educational Ethic of Care," Journal of Management Education, vol. 41, No5, pp. 669-686, 2017.

[13] L.I. Ilyashenko, O.I. Vaganova, Z.V. Smirnova, N.V. Bystrova, S.N. Kaznacheeva, "Students' creative abilities development in higher educational institution," Amazonia Investiga, vol. 8, Issue: 22, pp. 701710, Sep-Oct, 2019.

[14] B.Z. Flow, "Leadership and serious games - a pedagogical perspective," World Journal of Science, Technology and Sustainable Development, vol. 14 Issue 2/3. pp. 204-217, 2017. DOI: https://doi.org/10.1108/WJSTSD-05-2016-0035.

[15] F. M. Angels, M.A. María-Jesús, R.G. Eva, "The comprehensive implementation of generic skills in cross business degrees: The experience of the faculty of Economics and Business of the UOC,
"Intangible Capital, vol. 11, Issue 4, pp. 589-611, 2015. DOI: http://dx.doi.org/10.3926/ic.623.

[16] E-B. Ricardo, S. Miguel-Angel, “An innovation activity model for Very Small Entities in the software sector: an empirical study," R\&D Management, vol. 47, Issue 5, pp. 671-781, 2017. DOI: 10.1111/radm.12226.

[17] K. Yongjae, "The effect of process management on different types of innovations: An analytical modeling approach," European Journal of Operational Research,. vol. 262, Issue 2, pp. 771-779, 2017. DOI: https://doi.org/10.1016/j.ejor.2017.03.064.

[18] S.A. Ermakov, T.V. Svadbina, O.A. Nemova, V.A. Karnaukhova, G.A. Kazantseva, A.A Karpukova, "Foundations of the favorable human life path AD, "Alta-Journal Of Interdisciplinary Research, vol. 9, Issue: 1, pp. 55-57, 2019.

[19] D. McIver, S. Fitzsimmons, D. Flanagan, "Instructional Design as Knowledge Management: A Knowledge-in-Practice Approach to Choosing Instructional Methods," Journal of Management Education, vol. 40(1), pp. 47-75, 2016. DOI: 10.1177/1052562915587583.

[20] R. Morlhon., R..Pellerin, M. Bourgault, "Defining Building Information Modeling implementation activities based on capability maturity evaluation: a theoretical model," International Journal of Information Systems and Project Management, vol. 3, no1, pp. 51-65, 2015.

[21] G. Tan, "Managing Creativity in Organizations: A Total System Approach," Creativity and Innovation Management., vol. 7(1), pp. 2331, 1998.

[22] M.V. Arkhipova, E.E. Belova, Y.A.Gavrikova, T.E. Nikolskaya, T.N. Pleskanyuk, "Overview of the Educational Motivation Theory: A Historical Perspective," Lecture Notes in Networks and Systems, vol. 87, pp. 324-331, 2020.

[23] M.L. Gruzdeva, N.I. Tukenova, "Analysis of the current state of research and development in the field of building information and educational environments of higher educational institutions," Vestnik of Minin University, vol. 7, no 2, pp.1-12, 2019. 